Mehmet Akif Ersoy Üniversitesi Fen Bilimleri Enstitüsü Dergisi 10(1): 28-33 (2019)

The Journal of Graduate School of Natural and Applied Sciences of Mehmet Akif Ersoy University 10(1): 28-33 (2019)

Araştırma Makalesi / Research Paper

\title{
Toros Sediri'nde (Cedrus libani A. Rich.) Fidan Tipi x Fidan Morfolojisi Etkileşimi
}

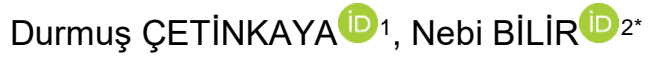 \\ ${ }^{1}$ Çukurova Üniversitesi, Aladağ Meslek Yüksekokulu, Adana \\ ${ }^{2}$ Isparta Uygulamalı Bilimler Üniversitesi, Orman Fakültesi, Isparta \\ Geliş Tarihi (Received): 09.01.2019, Kabul Tarihi (Accepted): 18.02.2019 \\ $\square$ Sorumlu Yazar (Corresponding author*): nebibilir@isparta.edu.tr \\ (C) +902462113837 且 +902462373948
}

öz

Tohum meşceresi orijinli Toros Sediri'nin (Cedrus libani A. Rich) 1+0 yaşlı tüplü ve çıplak köklü fidanları üzerinde gerçekleştirilen bu çalışmada fidan tipinin morfolojik fidan özelliklerine (boy, kök boğazı çapı, kök uzunluğu, dal, tomurcuk ve kök sayıları ile kuru ve yaş ağırlıklar) olan etkisi araştıııımıştır. Çalışma sonucunda tüplü fidanların çıplak köklü fidanlara göre daha yüksek gelişim gösterdiği belirlenmiştir. Örneğin fidan boyu ve kök boğazı çapı, tüplü fidanlarda 13,1 cm, 3,02 mm bulunurken çıplak köklü fidanlarda $6,2 \mathrm{~cm}$ ve 2,07 mm bulunmuştur. Bununla birlikte, Türk Standartları Enstitüsü fidan kalite sınıflarına göre tüplü fidanların tamamının dikime elverişli olduğu belirlenirken, çıplak köklü fidanların boy için \%45’i, kök boğazı çapı için \%53'ünün dikime elverişsiz olduğu belirlenmiştir. Uygulanan varyans analizi sonucunda çalışmaya konu özellikler bakımından fidan tipleri arasında istatistiksel bakımdan anlamlı $(p<0.05)$ fark belirlenirken; korelasyon analizi sonucunda özellikler arasında genel olarak istatistiksel bakımdan anlamlı $(p<0.05)$ pozitif ilişkiler ortaya çıkmıştır.

Anahtar Kelimeler: Fidanlık, Cedrus libani, Kalite, Toros Sediri, Varyasyon

\section{Interaction of Seedling Type and Seedling Morphology in Taurus Cedar (Cedrus libani A. Rich.)}

\begin{abstract}
This study was carried out on $1+0$ year containerized and bare-root seedlings, originated from a seed stand of Taurus cedar (Cedrus libani A. Rich) to estimate effect on seedling morphology (height, root-collar diameter, root length, numbers of root and buds, fresh and dry weights). Containerized seedlings showed higher growth performance than bare-root seedlings. For instance, averages of height and root-collar diameter were $13.1 \mathrm{~cm}$ and $3.02 \mathrm{~mm}$ in containerized seedlings, while they were $6.2 \mathrm{~cm}$ and $2.07 \mathrm{~mm}$ in bare-root seedlings. $45 \%$ of seedling for height and $53 \%$ for root-collar diameter of bare-root seedlings were cull/unsuitable for plantation, while they was no any cull seedlings in containerized according to quality classes of Turkish Standard Institute. Significant difference $(p<0.05)$ between seedling types for the characteristics were found according to results of variance analysis. Results of correlation analysis showed generally positive and significant $(p<0.05)$ relations among the characteristics in both seedling types.
\end{abstract}

Keywords: Nursery, Cedrus libani, Quality, Taurus cedar, Variation 


\section{Giriş}

Yaklaşık 22 milyon ha büyüklüğünde olan Türkiye ormanlarının, \%53,3'ü (11,6 milyon ha) verimli olup, $\% 46,7^{\prime}$ lik kısmı ise verimsiz yani ağaçlandırmaya konu alanlardandır (Anonim, 2015). "Türkiye Milli Ağaç Islahı Programı"nın öncelikli (Koski ve Antola, 1993) ve ekonomik değeri bakımından önemli bir türümüz olan çalışmaya konu Toros sedirinin (Cedrus libani A. Rich.), ülkemizde 220328 ha normal koru ve 243193 ha bozuk koru olmak üzere 463521 ha saf ormanı bulunmaktadır (Anonim, 2015). Ancak, ülkemizde bu türün potansiyel sahasının 600000 ha üzerinde olduğu belirtilmektedir (Boydak ve Çalıkoğlu, 2008). Türün ekonomik ve sosyokültürel önemi ile verimsiz orman alanlarının genişliği, ağaçlandırma çalışmalarının önem ve ivediliğini de artırmaktadır. Uygulanan ve uygulanacak ağaçlandırma çaıışmalarında fidan tip, morfoloji ve kalitesi başarıyı etkileyen önemli faktörlerden biridir. Bu çalışmalarda kullanılan tüplü veya çıplak köklü fidanların birbirlerine olan ekonomik ve biyolojik üstünlük ve olumsuz yönleri birçok çalışmada ele alınmasına karşın fidan tiplerinin karşılaştırılması veya türün fidan morfoloji, fizyolojisi ve kalitesine yönelik sınırlı sayıda çalışma yapılmıştır (Eler ve ark., 1993; Ayıntaplı, 1995; Bilir, 1997; Demirci ve Bilir, 2001; Semerci, 2002; Yıldız, 2005; Bilir ve Çetinkaya, 2018). Bu bağlamda çalışmada, Adana-Kıcak Orman Fidanlığı'nda yetiştirilen tohum meşceresi orijinli $1+0$ yaşı tüplü ve çıplak köklü Toros sediri fidanlarının morfolojik özelliklerinin belirlenmesi, irdelenmesi ve karşılaştırılarak; türün fidanlık tekniği ile verimsiz ormanlarının ıslahı ve ülkemizdeki ağaçlandırma çalışmalarına katkı sağlanması amaçlanmıştır.

\section{MATERYAL VE YÖNTEM}

Çalışmada materyal olarak, Adana-Kıcak Orman Fidanlığında (37³4' 40" Kuzey enlemi, 35¹2 '45" Doğu boylamı, $980 \mathrm{~m}$ yükseltili) üretilen Adana-Feke tohum meşceresi orijinli ( $37^{\circ} 49^{\prime} 22^{\prime \prime}$ Kuzey enlemi, 35³8' 34" Doğu boylamı, $1376 \mathrm{~m}$ yükseltili) $1+0$ yaşlı tüplü ve çıplak köklü Toros sediri fidanları kullanılmıştır (Şekil 1).

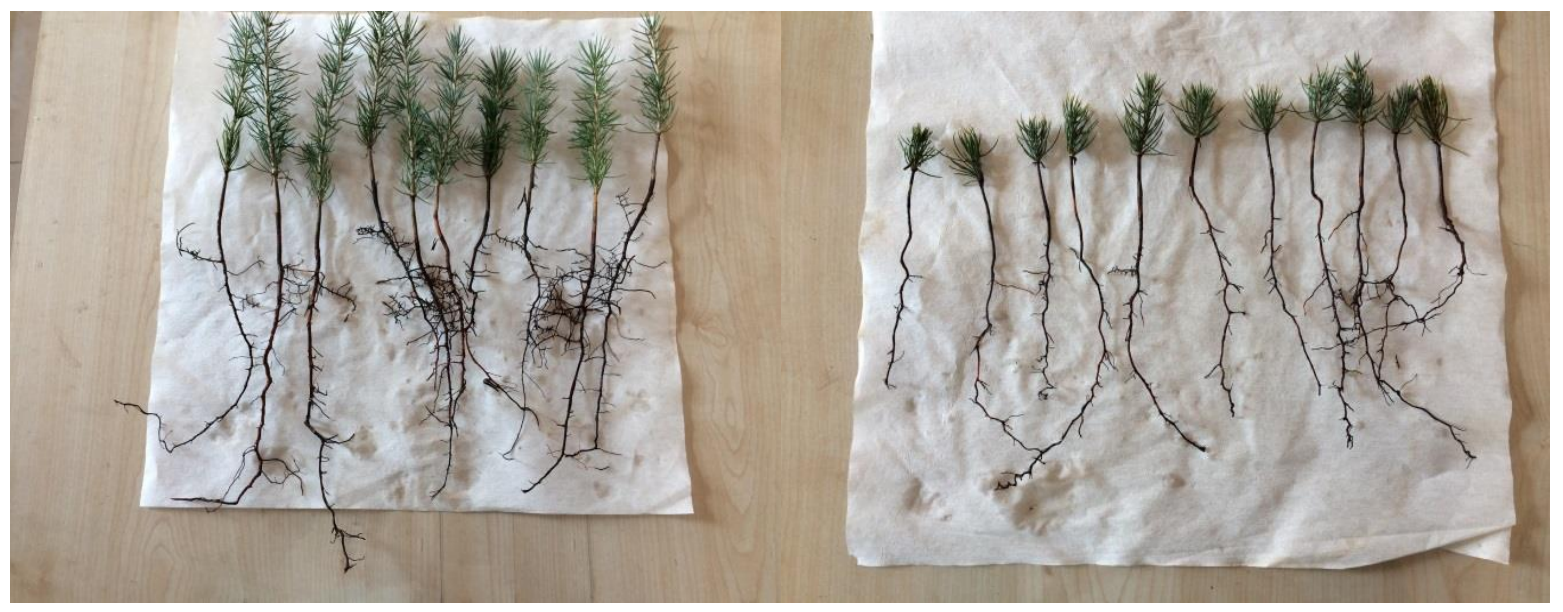

Şekil 1. Çalışmada kullanılan tüplü (sol şekil) ve çıplak köklü (sağ şekil) Toros sediri fidanları

Türün Adana-Kıcak Orman Fidanlığında yetiştirilen 1+0 yaşlı tüplü (TP) ve çıplak köklü (ÇK) fidanlarından 2018 yılı büyüme dönemi sonunda rastgele 100'er fidan örneklenmiştir. Fidanlarda kök boğazı çapı (KBÇ, 0,1 $\mathrm{mm}$ hassasiyetle), fidan boyu (FB, $0,1 \mathrm{~cm}$ hassasiyetle), gövde üzerinde bulunan $1 \mathrm{~cm}$ 'den uzun dal sayısı (DS), kök üzerindeki $1 \mathrm{~cm}$ 'den uzun yan kök sayısı (YKS), en uzun kök uzunluğu (EUK, 0,1 cm hassasiyetle), gövde taze ağırlığı (GTA, 0,001 g hassasiyetle), kök taze ağırlığı (KTA, 0,001 g hassasiyetle), fidan taze ağırlığı (FTA, $0,001 \mathrm{~g}$ hassasiyetle), gövde kuru ağırlığı (GKA, 0,001 $\mathrm{g}$ hassasiyetle), kök kuru ağırlığı (KKA, 0,001 g hassasiyetle), fidan kuru ağırlığı (FKA, 0,001 g hassasiyetle) ve tomurcuk sayımı (TS) ölçümleri gerçekleştirilmiştir. Fidanların morfolojik özelliklerinin ölçümü Çukurova Üniversitesi Aladağ MYO Ormancılık Programı laboratuvarında $0,01 \mathrm{~mm}$ duyarlıklı kumpas, $0,1 \mathrm{~cm}$ duyarlıklı cetvel ve $0.001 \mathrm{~g}$ duyarlııklı elektronik terazi ile gerçekleştirilirken, fidanlar fırın kurusu hale 24 saat ve $105 \pm 2^{\circ} \mathrm{C}$ 'de kullanılan etüv yardımıyla getirilmiştir.

Elde edilen veriler SPSS paket programında değerlendirilerek fidan tipine ilişkin temel istatistiksel değerler belirlenmiştir. Çalışmaya konu özellikler bakımından fidan tipleri basit (ANOVA) varyans analizi ile karşılaştırılarak; özellikler arasındaki ilişkiler korelasyon analizi ile belirlenmiştir (Özdamar, 1999). Bununla birlikte elde edilen veriler ışığında fidanların tipine göre, boy ve kök boğazı çapı bakımından Türk Standartları Enstitüsü'nün (TSE) kalite sınıflarına dağılımı belirlenmiştir (Tablo 1) (Anonim, 1988). 
Tablo 1. TSE'ye göre fidan boyu ve kök boğazı çapı için Toros sediri kalite sınıfları

\begin{tabular}{ccc} 
& \multicolumn{2}{c}{ Özellik } \\
Kalite sınıfı & Fidan boyu (FB, cm) & Kök boğazı çapı (KBÇ, mm) \\
\hline I. sınıf & $8 \leq$ & $2 \leq$ \\
II. sınıf & $8>$ FB $\geq 6$ & - \\
Elverişsiz & $6>$ & $2>$
\end{tabular}

\section{BULGULAR VE TARTIŞMA}

\section{Morfolojik Özellikler ve Fidan Kalitesi}

Çalışma sonucunda tüplü fidanların çıplak köklü fidanlara göre daha yüksek gelişim gösterdiği belirlenmiştir. Örneğin, ölçüm yapılan fidanlarda ortalama fidan boyu ve kök boğazı çapı değerleri $9,7 \mathrm{~cm}$ ve $2,55 \mathrm{~mm}$ bulunurken bu değerlerin tüplü fidanlarda $13,1 \mathrm{~cm}$ ve 3,02 $\mathrm{mm}$, çıplak köklü fidanlarda ise $6,2 \mathrm{~cm}$ ve $2,07 \mathrm{~mm}$ olduğu ortaya çıkmıştır (Tablo 2). Türün 5 fidanlıkta ve 2+0 yaşı ı fidanlarında yapılan bir çalışmada ortalama fidan boylarının $7,6 \mathrm{~cm}-23,6 \mathrm{~cm}$ arasında değiştiği belirlenmiştir ve aynı çalışmada sadece bir fidanlıkta ölçülen kök boğazı çapı ise $3,2 \mathrm{~mm}$ olarak bulunmuştur (Tunçtaner, 1985). Toros sedirinde yapılan bir başka çalışmada ise, $1+0$ yaşındaki ortalama fidan boyu $13,1 \mathrm{~cm}$, fidan çapı ise 2,1 mm bulunmuştur (Ayıntaplı, 1995). Türün tohum bahçesi orijinli $1+0$ yaşlı tüplü ve çıplak köklü fidanlarında yapılan çalışmada da tüplü fidanların fidan boyu
(10,3 cm ve $7,3 \mathrm{~cm})$ ve kök boğazı çapı $(3,1 \mathrm{~mm}$ ve 2,1 $\mathrm{mm}$ ) bakımından çıplak köklü fidanlara oranla daha yüksek gelişim gösterdiği belirlenmiştir (Bilir ve Çetinkaya, 2018).

Tüplü fidanlarda $3,30 \mathrm{~g}$ bulunan fidan taze ağırlığı, çıplak köklü fidanlarda $0,88 \mathrm{~g}$ bulunurken, fidan kuru ağırlıkları fidan tipleri için sırasıyla $1,52 \mathrm{~g}$ ve $0,45 \mathrm{~g}$ bulunmuştur (Tablo 2). Bununla birlikte tüplü fidanlar \%54 su içeriğine sahipken çıplak köklü fidanların \%49 su içeriğine sahip olduğu belirlenmiştir. Tüplü fidanların çıplak köklü fidanlara göre daha yüksek gelişim gösterdiğine ilişkin benzer bulgular, Dilaver (2015) tarafından Kızılçam (Pinus brutia Ten.) üzerinde gerçekleştirilen bir çaIışmada da belirlenmiştir. Aynı çalışmada tohum bahçesi orijinli tüplü fidanlar çıplak köklü fidanlara oranla boy bakımından yaklaşık \%50 daha fazla gelişim gösterdiği ortaya çıkmıştır.

Tablo 2. Morfolojik özelliklere ilişkin ortalama ve minimum-maksimum değerleri

\begin{tabular}{ccccccc}
\hline \multirow{2}{*}{ Özellikler } & \multicolumn{2}{c}{ TÜPLÜ } & \multicolumn{2}{c}{ ÇIPLAK KÖKLÜ } & \multicolumn{2}{c}{ GENEL } \\
& Ort. & Min - Mak. & Ort. & Min - Mak. & Ort. & Min - Mak. \\
\hline KBÇ $(\mathrm{mm})$ & 3,02 & $2,02-4,45$ & 2,07 & $1,16-4,40$ & 2,55 & $1,16-4,45$ \\
FB $(\mathrm{cm})$ & 13,10 & $6,40-19,90$ & 6,20 & $2,40-9,60$ & 9,65 & $2,40-19,90$ \\
DS & 0,97 & $0-5$ & 0,31 & $0-2$ & 0,64 & $0-5$ \\
YKS & 4,62 & $2-8$ & 2,1 & $1-4$ & 3,34 & $1-8$ \\
EUK $(\mathrm{cm})$ & 6,88 & $3,60-12,30$ & 3,26 & $1,10-7,40$ & 5,07 & $1,10-12,30$ \\
GTA $(\mathrm{g})$ & 2,15 & $0,99-3,92$ & 0,62 & $0,25-7,10$ & 1,38 & $0,25-7,10$ \\
KTA $(\mathrm{g})$ & 1,17 & $0,44-2,46$ & 0,32 & $0,17-0,67$ & 0,75 & $0,17-2,46$ \\
FTA $(\mathrm{g})$ & 3,30 & $1,51-6,16$ & 0,88 & $0,43-1,87$ & 2,09 & $0,43-6,16$ \\
GKA $(\mathrm{g})$ & 0,95 & $0,46-1,68$ & 0,25 & $0,12-0,50$ & 0,60 & $0,12-1,68$ \\
KKA $(\mathrm{g})$ & 0,56 & $0,22-1,12$ & 0,20 & $0,10-0,36$ & 0,38 & $0,10-1,12$ \\
FKA $(\mathrm{gr})$ & 1,52 & $0,73-2,65$ & 0,45 & $0,25-0,86$ & 0,98 & $0,25-2,65$ \\
TS & 1,74 & $1-3$ & 1,35 & $1-3$ & 1,55 & $1-3$ \\
\hline
\end{tabular}

Çalışmaya konu özellikler bakımından fidan tipi içinde ve arasında geniş farklılıklar olduğu ortaya çıkmıştır (Tablo 2). Uygulanan varyans analizi sonucunda da çalışmaya konu özelliklerin tamamı bakımından fidan tipleri arasında istatistiksel bakımdan $(p \leq 0.05)$ anlamlı fark olduğu belirlenmiştir. Benzer sonuçlar türün tohum bahçesi orijinli 1+0 yaşlı tüplü ve çıplak köklü fidanlarında da belirlenmiştir (Bilir ve Çetinkaya, 2018). Bu sonuçlar türün geniş bir genetik tabana sahip olduğunu göstermektedir. Geniş varyasyon Dilaver (2015) tarafından tüplü ve çıplak köklü Kızılçam fidanları üzerinde gerçekleştirilen çaIışmada da tahmin edilmiştir.

Fidanların Türk Standartları Enstitüsü'nün boy ve kök boğazı çapı kalite sınıflarına (Tablo 1) göre yapılan dağılımları sonucunda, tüplü fidanların tamamının dikime 
elverişli olduğu belirlenirken, çıplak köklü fidanların boy bakımından $(6 \mathrm{~cm}>\mathrm{FB})$ için \%45'inin, kök boğazı çapı bakımından (2 $\mathrm{mm}>\mathrm{KBÇ}$ ) ise \%53'ünün dikime elverişsiz olduğu belirlenmiştir. Bununla birlikte, boy bakımından (8 cmsFB) tüplü fidanların \%87'si 1. sınıf fidan sınıfında yer alırken, çıplak köklü fidanların \%9'u 1. sınıf fidan sınıfında yer almıştır. Eler ve ark. (1993) 2+0 yaşlı Toros sediri fidanları üzerinde gerçekleştirilen kalite sınıflamasında kalite kriteri olarak fidan boyu ve kök boğazı çapı esas alınmıştır. Çalışmada, fidan boyu 24 $\mathrm{cm}$ 'den daha uzun olan fidanlar iyi kaliteli, $16-24 \mathrm{~cm}$ arasında olanlar orta kaliteli ve $16 \mathrm{~cm}$ 'den kısa fidanlarda fena kaliteli olarak ayrılmıştır. Kök boğazı çapına göre ise kök boğazı çapı $6 \mathrm{~mm}$ 'den fazla olan fidanlar iyi kalitede, 4-6 $\mathrm{mm}$ arasında olanlar orta kaliteli ve $4 \mathrm{~mm}$ 'den kısa olan fidanlar ise fena kaliteli olarak sınıflara ayrılmıştır. Bilir (1997) tarafından 2+0 yaşlı çıplak köklü Toros sediri fidanları üzerinde gerçekleştirilen çalışmada TSE 'ye göre fidanların boy bakımından $\% 75$ 'i I. sınıf, $\% 12$ 'si II. sınıf, \%11'i III. sınıfta, \%3'ünün dikime elverişsiz fidan sınıfında yer aldığı; kök boğazı çapı bakımından ise fidanların \%95'inin kaliteli, \%5'inin ise dikime elverişsiz fidan olduğu belirlenmiştir. Türün tohum bahçesi orijinli 1+0 yaşlı tüplü ve çıplak köklü fidanlarında yapılan çalışmada da çıplak köklü fidanların boy bakımından $\% 12$ 'sinin, kök boğazı çapı bakımından ise \%41'inin dikime elverişsiz olduğu ve bu değerlerin tüplü fidanlar için sırasıyla $\% 7$ ve $\% 9$ olduğu ortaya çıkmıştır (Bilir ve Çetinkaya, 2018).
Kızılçam üzerinde gerçekleştirilen bir çalışmada fidanların Türk Standartları Enstitüsü'nün boy ve kök boğazı çapı kalite sınıflarına göre dağılımlarının belirlenmesi sonucunda, en kaliteli fidanların tohum bahçesinden elde edilen tüplü fidanlarda olduğu ortaya çıkmıştır (Dilaver, 2015).

\section{Özellikler Arasındaki İlişkiler}

Çalışmaya konu özellikler arasındaki ilişkileri belirlemek amacıyla uygulanan Korelasyon analizi sonucunda gerek tüplü ve gerekse çıplak köklü fidanlarda özellikler arasında genel olarak istatistiksel bakımdan anlamlı $(p<0.05)$ pozitif ilişkiler belirlenmiştir (Tablo 3$)$. Benzer sonuçlar Bilir ve Çetinkaya (2018) tarafından türün tohum bahçesi orijinli $1+0$ yaşlı fidanlarında da boy ve kök boğazı çapı arasında tahmin edilmiştir Değişik orman ağacı türlerinde yapılan çalışmalarda da fidan morfolojik özellikleri arasında anlamlı pozitif ilişkiler belirlenmiştir (Eyüboğlu ve Karadeniz, 1987; Morris ve ark., 1990; Dilaver, 2015). Bu sonuçlar zaman tasarrufu sağlanması, ekonomikliği ve kolaylığı nedeniyle sadece fidan boyu ve kök boğazı çapının ölçümüyle diğer özelliklerin de tahmin edilebileceğini göstermektedir. Bu bağlamda, ölçüm kolaylığı ve pratikliği nedeniyle fidan boyunun, fidan taze ve kuru ağırlıkları ile olan ilişkisi Regresyon analizi ile Şekil 2'de görselleştirilmiştir.

Tablo 3. Tüplü (diyagonal üstü) ve çıplak köklü (diyagonal altı) fidanlarda özellikler arasındaki ilişkileri

\begin{tabular}{|c|c|c|c|c|c|c|c|c|c|c|c|c|}
\hline$r$ & KBÇ & FB & DS & YKS & EUK & GTA & KTA & FTA & GKA & KKA & FKA & TS \\
\hline KBÇ & - & $.43^{\star \star}$ & $.51^{\star *}$ & $.47^{\star *}$ & $.18^{\mathrm{NS}}$ & $.80^{\star \star}$ & $.84^{\star \star}$ & $.85^{\star \star}$ & $.73^{\star \star}$ & $.82^{\star \star}$ & $.84^{* *}$ & $22^{*}$ \\
\hline $\mathrm{FB}^{3}$ & $.40^{\star *}$ & - & $.19^{N S}$ & $.17^{\mathrm{NS}}$ & $20^{*}$ & $.56^{\star *}$ & $.53^{\star \star}$ & $.57^{\star *}$ & $.56^{\star \star}$ & $.53^{\star \star}$ & $.58^{* *}$ & $.15^{\mathrm{NS}}$ \\
\hline DS & $.30^{\star *}$ & $.35^{\star *}$ & - & $27^{* \star}$ & $.05^{\mathrm{NS}}$ & $.46^{\star *}$ & $.46^{\star \star}$ & $49^{\star *}$ & $.42^{\star \star}$ & $.48^{\star \star}$ & $.49^{* *}$ & $.21^{*}$ \\
\hline YKS & $.41^{\text {** }}$ & $.26^{\star \star}$ & $.26^{*}$ & - & $.15^{\mathrm{NS}}$ & $.37^{\star *}$ & $.45^{\star \star}$ & $.41^{\text {** }}$ & $.34^{* *}$ & $.45^{\star \star}$ & $.41^{\text {** }}$ & $.03^{\mathrm{NS}}$ \\
\hline EUK & $.65^{\text {** }}$ & $.22^{*}$ & $20^{*}$ & $.28^{* *}$ & 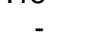 & $.25^{\star}$ & $.22^{*}$ & $24^{*}$ & $.22^{*}$ & $.21^{*}$ & $.24^{*}$ & $.07^{\mathrm{NS}}$ \\
\hline GTA & $.19^{\mathrm{NS}}$ & $31^{\text {** }}$ & $.05^{\mathrm{NS}}$ & $.10^{\mathrm{NS}}$ & $.17^{\mathrm{NS}}$ & - & $.88^{* *}$ & $.96^{* *}$ & $.92^{\star *}$ & $.86^{\star *}$ & $.96^{* *}$ & $21^{*}$ \\
\hline KTA & $.94^{* *}$ & $.38^{\star *}$ & $28^{* *}$ & $.46^{* *}$ & $.57^{* *}$ & $.18^{\mathrm{NS}}$ & 0 & $.97^{\star *}$ & $.83^{\star \star}$ & $.98^{\star \star}$ & $.96^{\star \star}$ & $.14^{\mathrm{NS}}$ \\
\hline FTA & $.87^{\star \star}$ & $.65^{\star \star}$ & $.35^{\star *}$ & $.44^{\star \star}$ & $.54^{\star \star}$ & $.32^{\star \star}$ & $.87^{\star \star}$ & - & $.90^{\star \star}$ & $.94^{\star \star}$ & $.99^{\star \star}$ & $.18^{\mathrm{NS}}$ \\
\hline GKA & $.70^{\star *}$ & $.65^{\star \star}$ & $29^{\star *}$ & $.37^{\star \star}$ & $.42^{\text {** }}$ & $.37^{\star \star}$ & $.69^{\star \star}$ & $.90^{\star *}$ & - & $.79^{\star \star}$ & $.90^{\star \star}$ & $.17^{\mathrm{NS}}$ \\
\hline KKA & $.75^{\star \star}$ & $25^{\star}$ & $28^{\star *}$ & $.41^{\star \star}$ & $.42^{* \star}$ & $.21^{*}$ & $.81^{\star \star}$ & $.68^{\star *}$ & $.49^{\star \star}$ & - & $.95^{\star \star}$ & $.15^{\mathrm{NS}}$ \\
\hline FKA & $83^{\star \star}$ & $.56^{\star *}$ & $33^{\star *}$ & $44^{\star \star}$ & $49^{* *}$ & $.34^{\star \star}$ & $.85^{\star \star}$ & $.93^{\star \star}$ & $.91^{\star *}$ & $.80^{\star *}$ & - & $.17^{\mathrm{NS}}$ \\
\hline TS & $24^{*}$ & $42^{\star \star}$ & $.07^{\mathrm{NS}}$ & $16^{\mathrm{NS}}$ & $02^{N S}$ & $.07^{\mathrm{NS}}$ & $.33^{\star \star}$ & $42^{\star \star}$ & $34^{\star \star}$ & $30^{\star *}$ & $37^{\star \star}$ & - \\
\hline
\end{tabular}



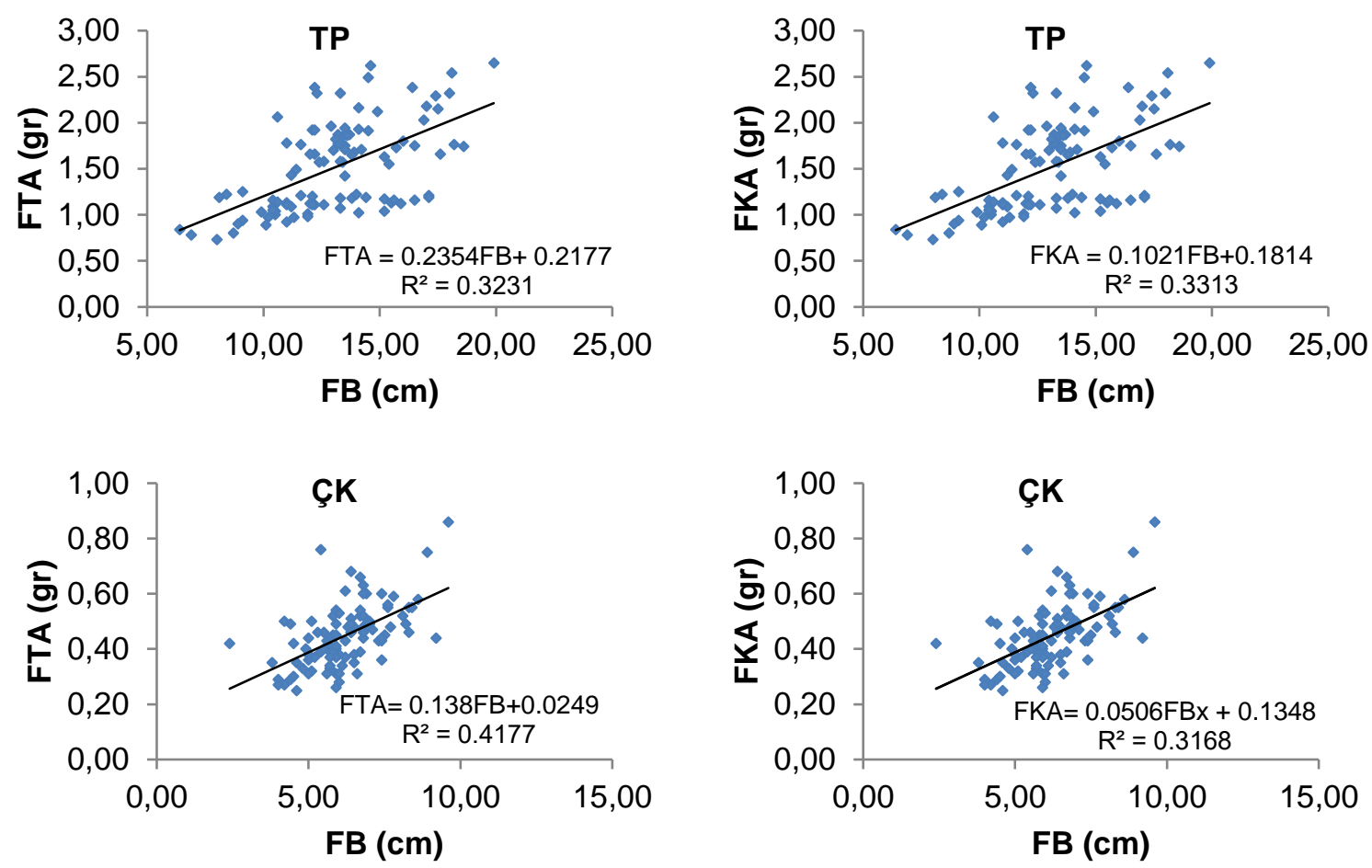

Şekil 2. Fidan tiplerine göre fidan boyu ile taze ve kuru fidan ağırlıkları arasındaki ilişkiler

\section{SONUÇLAR}

Tüplü ve çıplak köklü Toros sediri fidanları üzerinde gerçekleştirilen ve türün fidanlık tekniği, verimsiz ormanlarının ıslahı ile ülkemizdeki ağaçlandırma çalışmalarına katkı sağlanması amaçlanan bu çalışma sonucunda; tüplü fidanların çıplak köklü fidanlara oranla daha fazla gelişim gösterdiği ortaya çıkmıştır. Çalışmaya konu morfolojik özellikler bakımından fidan tipi içinde ve fidan tipleri arasında geniş farklııklar belirlenirken; bu farklıııklar uygulanan varyans analizi sonuçları ile de desteklenmiş ve fidan tipleri arasında istatistiksel bakımdan $(p \leq 0.05)$ anlamlı farklılıklar ortaya çıkmıştır. Fidanların Türk Standartları Enstitüsü'nün kalite sınıflarına göre dağılımı incelendiğinde, tüplü fidanların tamamının dikime elverişli olduğu belirlenirken, çıplak köklü fidanların boy bakımından \%45'inin, kök boğazı çapı bakımından ise \%53'ünün dikime elverişsiz olduğu ortaya çıkmıştır. Uygulanan Korelasyon analizi sonucunda özellikler arasında genel olarak istatistiksel bakımdan anlamlı $(p<0.05)$ pozitif ilişkiler belirlenmiştir.

\section{KAYNAKLAR}

Anonim (1988). Iğne Yapraklı Ağaç Fidanları, TS 2265/Şubat1988. Türk Standartları Enstitüsü Yayınları, Ankara.

Anonim (2015). Orman varlığımız. TC. Çevre ve Orman Bakanlığı Orman Genel Müdürlüğü, 28 s, Ankara.

Ayıntaplı, P. (1995). Serinyol ve Tekir Fidanlıklarında Üretilen Kızılçam, Anadolu Karaçamı ve Toros Sediri Fidanlarında
Kalite Sınıflaması Araştırmaları. Karadeniz Teknik üniversitesi Fen Bilimleri Enstitüsü. Yüksek Lisans Tezi. 115, Trabzon.

Bilir, N. (1997). Doğu Karadeniz Bölgesi'nde Toros Sediri (Cedrus libani A.Rich.) Orijin Denemeleri Fidanlık Aşaması. Karadeniz Teknik üniversitesi Fen Bilimleri Enstitüsü. Yüksek Lisans Tezi. 90, Trabzon.

Bilir, N., Çetinkaya, D. (2018). Variation of Morphology and Quality in 1+0 Year Containerized and Bare-Root Seedlings of Taurus Cedar (Cedrus libani A. Rich.). 4th International Conference Reforestation Challenges, p. 10, 19-23 June, Belgrade, Serbia.

Boydak, M., Çalıkoğlu, M. (2008). Toros Sedirinin (Cedrus Iibani A.Rich.) Biyolojisi ve Silvikültürü. Orman Genel Müdülüğü Yayınları, Ankara.

Demirci, A., Bilir, N. (2001). Yaşı 3-0 Olan Toros Sediri (Cedrus libani A. Rich.) Fidanlarında Orijinler Arası Farklılıklar. Turkish Journal of Agriculture and Forestry, 25:217-223.

Dilaver, M. (2015). Balıkesir-Dursunbey Orman Fidanlığında Üretilen Tohum Meşceresi ve Tohum Bahçesi Orijinli Kızılçam (Pinus brutia Ten.) Fidanlarında Morfolojik Ôzellikler. Süleyman Demirel Üniversitesi Fen Bilimleri Enstitüsü. Yüksek Lisans Tezi. 33, Isparta.

Eler, Ü., Keskin, S., Örtel, E. (1993). Toros sediri (Cedrus libani A. Rich.) Fidanlarında Kalite Sınıflarının Belirlenmesi Üzerine Araştırmalar. Ormancılık Araştırma Enstitüsü Dergisi, 240:81-105.

Eyüboğlu, A.K., Karadeniz, A. (1987). Doğu Kayınında (Fagus orientalis Lipsky. ) Dikim Anındaki Fidan Boyu ve Çapı İle Üç Yıllık Boy Büyümesi Arasındaki İlişkiler. Ormancılık Araştırma Enstitüsü Teknik Bülten Serisi, 185:5-13, Ankara. 
Koski, V., Antola, J. (1993). National tree breeding and seed production programme for Turkey 1994-2003. The Research Directorate of Forest Tree Seeds and Tree Breeding, Ankara.

Morris, D.M., Macdonald, G.B., Mcclain, K.M. (1990). Evaluation Of Morphological Attributes As Response Variables to Perennial Competition For 4 Years Old Black Spruce And Jack Pine Seedlings. Canadian Journal of Forest Research, 20 (11): 1696-1703.

Özdamar, K. (1999). Paket Programlar İle İstatistiksel Veri Analizi, Kaan Kitabevi, Eskişehir.
Semerci, A. (2002). Sedir (Cedrus libani A. Rich.) Fidanlarına Ait Bazı Morfolojik ve Fizyolojik Karakteristikler İle İç Anadolu'daki Dikim Başarısı Arasındaki İlişkiler. İç Anadolu Ormancılık Araştırma Enstitüsü Yayınları, Teknik Bülten, 279, 142, Ankara.

Tunçtaner, İ. A. (1985). Bazı Fidanlıklarımızdaki Çeşitli İbreli Fidanların Kaliteleri İle Fidanlarla Topraktan Tüketilen Bazı Besin Maddeleri ve Gübreleme. Orman Mühendisliği Dergisi, 22(12):27-35.

Yıldız, D. (2005). Bazı Yetiştirme Tekniklerinin Toros Sediri (Cedrus libani A. Rich.)'nde Fidan Morfolojisine Etkisi. Süleyman Demirel Üniversitesi Fen Bilimleri Enstitüsü. Yüksek Lisans Tezi. 105, Isparta. 